\title{
PATTERNS OF URBAN FIRE OCCURENCE IN IASI CITY (ROMANIA)
}

\author{
Anca - Teodora Bulai ${ }^{1}$, Lucian Roșu ${ }^{1}$, Alexandru Bănică ${ }^{1,2}$
}

Keywords: fire incidents, temporal distribution, spatial analysis, location quotient, Iasi City

\begin{abstract}
Fire incidents are a problem of major importance for cities, as they affect the lives of a large population and produce significant material damages. Assessing the temporal and spatial distribution of fires is an important stage in order to efficiently manage this issue. Using a comprehensive database for a five year period, the present study tries to identify certain patterns and specificities by analyzing the occurrence of urban fires, grouped by their main causes and damages, at different time scale and integrating the information from street level to urban district and, finally, at city level.

The spatial distribution of the number of fires follows the center-periphery model, overlapping the neighborhoods with multiple functions (residential, administrative and cultural). The industrial area also concentrates a bigger number of fires, these brownfields being used by homeless population which make use of garbage as fire material. Applying the location quotient was an opportunity to highlight cross-scale the concentration of fires and revealed that the neighborhoods located at the periphery are more vulnerable to fires. The results can be used for further, more comprehensive studies of urban fire risk assessment and can also became the basis for (re)configuring the emergency services, in particular, and urban planning, in general.
\end{abstract}

\section{Introduction}

Fire incidents represent a topic of major interest as they are a significant threat to life and property, causing injuries and deaths, psychological and economic damage, important destruction upon both natural and build environment ("Bulletin World Fire Statistic" 2014, Yao \& Zang, 2016). Scholars show a great interest in analyzing fire incidents and their related issues, the vast majority of papers focusing on forest fire (Stephens et al., 2016; Keenan, 2015; Ganteaume et al., 2013), but at least a similar attention should be paid to urban fires occurrence.

\footnotetext{
${ }^{1}$ Alexandru Ioan Cuza University of Iaşi, Faculty of Geography and Geology, bulaianca4@gmail.com ${ }^{2}$ Romanian Academy - Iași Branch, Geography Collective, Iasi
} 
However, in the past years a significant number of works focused on urban fire risk have emerged, especially seeking to highlight the effects of socioeconomic factors on fire incidents (Jennings, 1999; Clark et al., 2015). Despite the relatively new scientific diffuseness of this topic, the temporal and spatial patterns of fire incidents have not been taken into account for studies at larger scales, in order to really reach - and be taken into account by - the local and regional authorities.

At urban scale, it is very important to assess the location and frequency of fire incidents in order to identify vulnerable groups, so that authorities might take the proper measures to reduce the number of casualties and the material loss. The analysis of the location and dynamics of fire incidents is, in this respect, the first step in revealing the main patterns and trends of urban fire occurrence (Chhetri et al., 2010, Corcoran, 2011).

In Romania, fire incidents represent a major risk that has to be taken into account at least at the seme level as other threats such as earthquakes or car accidents (Merciu et al., 2018, Benedek et al., 2016) . Between 2011 and 2015, an average number of 32,094 fires/year was recorded, involving an average annual number of 364 deaths and 593 non-fatal casualties (CTIF, 2017). According to the General Inspectorate for Emergency Situations (IGSU, 2016), in 2016 the average number of fires per day nationwide was 76, while 3084 people, of which 255 children were saved during fire-fighting interventions.

Between 2012 and 2016, in Iaşi County, 4302 interventions were registered, out of which $45.72 \%$ were fire incidents. The Municipality of Iaşi recorded 35.28 $\%$ of all fires; the number of casualties is lower compared to county levels. According to the daily newsletters of the fire department, in a five year period in Iaşi 8 deaths and 24 injured were registered, while in the county there were 30 deaths and 55 injured. As far as the value of the damages is concerned, quantitative data are not available, but there were many households that were damaged or destroyed and, in several cases, families have been left homeless in the past years.

Using the information provided by the firefighting department, the present paper evaluates, in a temporal and spatial manner, the concentration of fire occurrences inside the built-up area of Iasi Municipality in order to highlight the patterns and trends at the urban neighborhood/district level. The results of such an analysis can be used by policy makers for spatial targeting and prioritizing of preventive measures. Therefore, the main objectives of this paper are to establish whether there are certain patterns in the temporal and spatial distribution of the interventions and also to observe if there is a relationship between the location of different urban functional areas, the types of buildings or land use, and the incidence of fires.

\section{Theoretical Background}


Fires represent a significant threat to life and property, but they are not totally unpredictable or unavoidable. They are a rather complex issue, with temporal dynamics that are difficult to explain and a spatial distribution that is neither uniform nor random. Instead there are systematic variations in the nature and severity of fires in the space of urbanized areas (Jennings, 1999).

These variations are represented by linked economic, demographic and social characteristics of the residential areas. A significant number of studies found a relation between family structure and the rate of residential fires; also, it was established that there is a link between poverty, overcrowding, living under normal standards and a high risk of fires (Schaenman et al., 1997, Fahy \& Miller, 1989, Southwick \& Butler, 1985).

More comprehensively, (Nicopoulos et al., 1997) examined the relationship between the incidence of fires and the number of inhabitants, their age, ethnicity, school dropout rate, income, unemployment rate, type and age of the dwelling etc.

Other scholars also considered socio-economic factors such as poverty/deprivation, lack of education, ethnicity, overcrowding and the age of people and housing tenure (Corcoran et al., 2011).

In addition, a previous research that took place in the USA concluded that the areas with a large number of disadvantaged residents were more vulnerable to residential fires and has drawn attention to the impact of household factors such as family structure (FEMA, 1997).

Chhetri et al. examined the residential fires in Queensland; using the regression analysis, they linked the socio-economic disadvantages with the incidence of fires and discovered that five characteristics were associated with a greater risk of fire: unemployment, indigenous population, single parent families, and low proportion of families living in individual dwellings (Chhetri et al. 2010).

Fires in urban areas account for the vast majority of interventions involving fire departments and have the biggest collective impact on operational costs, property destruction and loss of life. The patterns created by the incidence of fires in urban areas is a research topic of great interest (Jennings, 2013; Corcoran et al., 2007; Asgary et al., 2010), with specialty literature offering several examples of studies in this direction.

In one of the most comprehensive papers in the field, Asgary et al. applied spatial, temporal and spatio-temporal techniques in order to illustrate how the patterns of structural fires in the city of Toronto vary during the day, the week and the month. For the temporal analysis they represented the data by hours, days, months and years, and for the spatial analysis they used methods like grid counting, kernel density estimator and average nearest neighbor distance. For the spatiotemporal analysis they used animated maps, isosurfaces and the co-map technique. The authors classified the fires in six different types (improper use, electrical or 
mechanical failure, vandalism, deficiencies in design, construction and maintenance, arson and children playing with fire) and created maps to illustrate the spatial intensity of the phenomenon using the kernel density estimator; they also mapped the events by taking into account the moment of the day (morning, noon, evening, night) and the month of the year. The results of this analysis concluded that there are significant differences regarding the incidents of fires in time. Moreover, the authors underlined the fact that the use of these methods can help the decision makers to propose preventive measures where are most needed and can also improve the allocation of resources in case of emergency (Asgary et al., 2010).

Consequently, other studies take into consideration the fire incidents that occurred in a certain area as one of the factors taken into account for localization optimization of urban fire stations (Yao et al., 2019).

Moreover, other researchers have used parametric analysis or complex computing models in order to assess or simulate urban fire spread in densely built urban areas (Li \& Davidson, 2013, Himoto \& Tanaka, 2008, Thomas et al., 2006).

Another method that offers information regarding the concentration of fires and the distribution pattern is the use of location quotient calculated for each type of fire. This coefficient determines the extent to which interventions are concentrated in each neighborhood or grid cell, by reference to the number of total interventions in the analyzed territory (Vasiliauskas \& Beconyte், 2015).

Beside the studies presented previously, which use various spatial approaches, there are also methods imported from other specialization fields. The location quotient, frequently used in economic studies, is a suitable indicator to highlight the extent to which incidents are concentrated in each neighborhood or grid cell, by reference to the number of total interventions in the analyzed territory (Vasiliauskas \& Beconyte, 2015).

In the context of a growing awareness of urban fires management, the studies of spatial and temporal dimensions of fire risk are becoming more and more important and acknowledgeable, which makes the necessity for research in this field even more prominent, also in countries like Romania, that do not have many scientific approaches of this issue.

\section{Methodology}

2.1 Study area. The area of study is represented by the Municipality of Iasi. Located in the North-East Region of Romania, Iasi is the second largest city in the country, with a population of approximatively 357.000 inhabitants. The largest majority of the population lives in multifamily residential buildings (74,3\%) (midrise, high-rise and dormitory) where approximately 260.000 inhabitants live in 2673 buildings or 95.000 units (apartments mostly). The rest of $25.7 \%$ of the 
population live in single family, detached or attached houses (Roșu and Blăgeanu, 2015). This type of housing is located on the outskirts of the city, with major differences between newly built districts (South-East and South) and districts with a mix of newly built houses and old houses (Northern and North-Western side of the city). A considerable number of individual dwellings are relatively old (more than 80 years), especially in the core urban area, while most of collective apartments are built in the past 60 years. Even so, there is a considerable number of inhabitants (43.000) living in buildings with an existing seismic risk (Banica et al. 2017).

During the past fifty years, few major hallmarks have shaped the present loose aspect of the city. The communism and post-communist periods influenced the urban morphology of the city the most. As a consequence of these influences, a large majority of residents are located in the western districts of the city (collective housing build for supplying the industrialized district), where the higher density of the population also increased the urban fire risk, raising new challenges to the fire and rescue services. The remaining districts have a heterogeneous functionality, with a rather chaotic distribution of different types of buildings. Evaluating the fire risk is even more problematic when taking into consideration the emergent districts from the outskirts of the city. The urban evolution of the city in the past 20 years highlights a major suburban sprawl with a major lack in infrastructural planning (Tsenkova \& Nedović-Budić, 2006). The chaotic development of the newly built districts at the outskirts together with the lack of planning regulation conduced to a difficult comprehension of the territory.

On the other hand, Iasi is a changing city, with a large share of the IT\&C sector, with a growing number of multinational companies sustained by a large academic community, showing diversity in terms of economic and functional evolution of the city.

The present study takes into account fire incidents that occurred in the built-up area of Iași Municipality between 2012 and 2016.

\subsection{Database}

The database was configured using the information extracted from daily newsletters of the fire department, which was organized in a framework containing information about the fire incidents such as the date and time of the intervention, actions taken at the scene, the type of fire, the material damages and the number of victims. The database consists of 694 firefighting interventions that took place in Iaşi City over a period of 5 years, from January 2012 until December 2016. At first, the incidents were analyzed without spatial localization, but, afterwards, the information about the address was useful to complete this process. Using the Google Earth software, every intervention was located at the address mentioned in 
the newsletters. There were some difficulties to locate the interventions where the address given was incomplete, given the fact that the number of the street was missing. In this case the solution was to place these incidents by taking into account the centroid of the street.

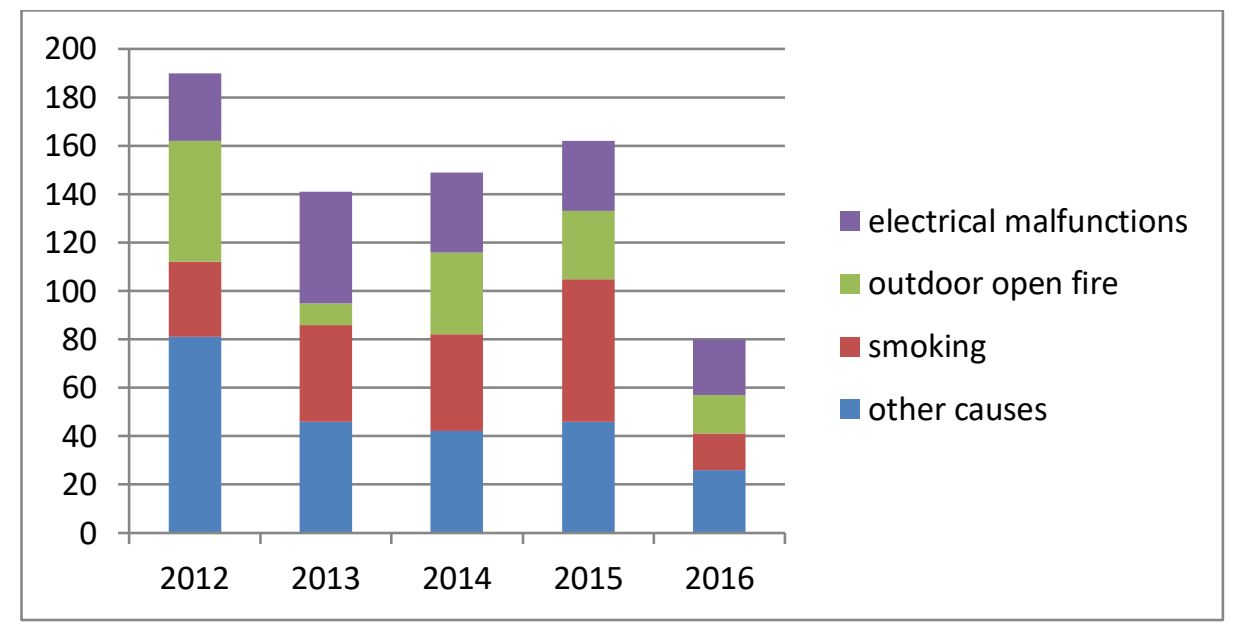

Figure 1 - Total number of firefighting interventions and the most important causes of ignition in Iasi (2012 - 2016)

The distribution of firefighting interventions varies from one year to another, but the differences are rather small. The noticeable gap was registered in 2016, which could suggest an under-registration of events, since for the rest of the period there are close values of the annual number of incidents. This difference can occur because not all the newsletters from 2016 were published on the fire department website. Figure 1 shows that the main cause of fire is variable from one year to another. The constant element for the whole analyzed period is the fact that electrical malfunctions, open fire and smoking remain the main causes of ignition in all the years and these exceed in number any other cause.

\subsection{Temporal and spatial distribution assessment}

Methodologically, the basic exploratory analysis of the present study was undertaken in two stages. First, a temporal assessment was accomplished by taking into account the frequencies of the fire incidents in Iași at different time scales. Secondly, the spatial distribution of fire occurrences was analyzed at neighborhood level in order to find the hotspots and the general patterns of their localization throughout the five years of observation. Finally, the purpose was to observe the temporal and spatial variations in the concentration of fire incidents. Determining 
locations and time intervals can generate solutions allowing for a decrease in the number of interventions in the following years.

The temporal analysis took into consideration the distribution of fire events in each of the five years, in each month of the year, on each day of the week and in intervals of three hours for each day. The graphic illustration for each temporal scale was useful in order to highlight differences and draw conclusion on the moment when fires predominantly occur in Iași city.

The spatial analysis made use of the location quotient index which was chosen because of its suitability for the envisaged assessment of fire occurrence.

The location quotient is an index used for comparing the importance of a phenomenon's share with the general phenomenon over a certain area. "The location quotient quantifies how concentrated a particular industry, cluster, occupation or demographic group is in a region compared to the nation. It can reveal what makes a particular region unique in comparison to the national average" (Sentz, 2018). In our case it was calculated for each type of fire and the main causes of fire at the neighborhood level compared to city level, and shows in which of the neighborhoods a type or a cause of fire is concentrated. The formula applied is:

$$
L Q i=\left(\frac{\frac{e i}{e}}{p o p i}\right) /\left(\frac{\frac{E i}{E}}{p o p}\right)
$$

where, $e_{i}-$ the number of fires of that type in the neighborhood

$\mathrm{e}-$ total number of fires in the neighborhood

pop $_{i}$ - the number of inhabitants in the neighborhood

$E i$ - the number of fires of that type in the city

$E$ - total number of fires in the city

pop - the number of inhabitants in the city;

Interpretation of $L Q$ results:

- If $L Q>1$ - in those neighborhoods that type of fire is more frequent compared to the values that is registered at city level

- If $\mathrm{LQ}=1$ - there is no difference between the neighborhood and the city

- If LQ $<1$ - in those neighborhoods that type of fire is less frequent compared to the city

First, the data at street level were summed up by neighborhood/city district. Then the method was used in order to show the degree of concentration of the phenomenon in each neighborhood compared to the occurrences at city level. The calculations and mapping of the results were done using the ArcGIS 10.4 software. 


\section{Results and findings}

3.1. Overview of the fire incidence in Iasi Municipality. In the analyzed period of 5 years, 694 fires were registered in Iasi City, the most frequent being the residential fires $(28,55 \%)$, vegetation fires $(16.37 \%)$, garbage containers and waste storage facilities fires $(12.31 \%)$ and vehicle fires $(9.13 \%)$.

The main causes of the fires registered are electrical malfunctions, open fire, smoking and unsupervised cooking machines. As far as the actual damage is concerned, only few of them were considered destructive from an economic point of view. In terms of human loss and injured people, there were 8 deaths caused by the fires. In 24 cases, the intervention of emergency medical assistance was necessary.

4.2 Temporal analysis. The aim of the temporal analysis is to observe whether there is a link between the number of fires and their occurrence in a certain year, month, day of the week or hour of the day.

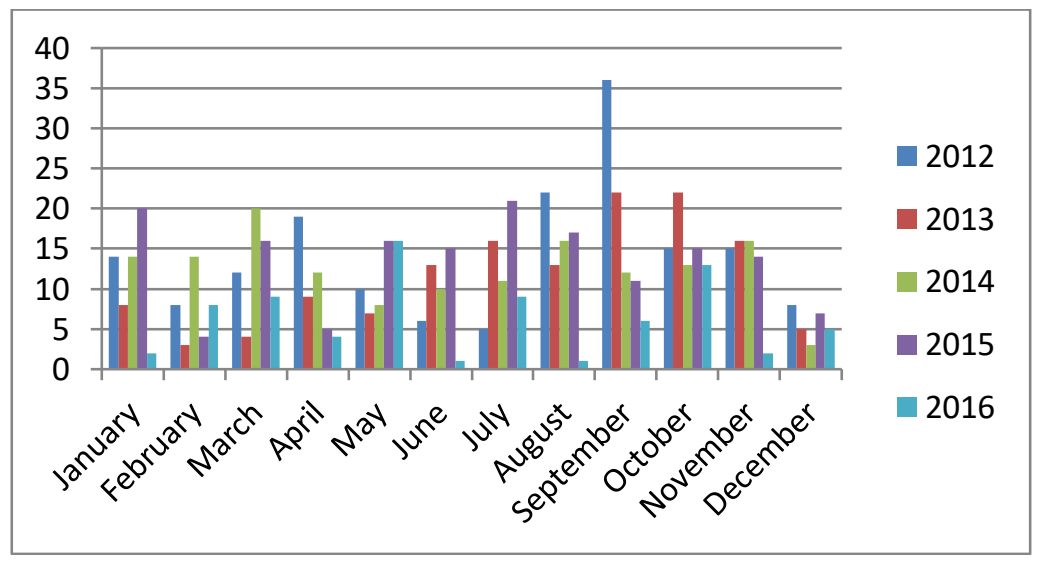

Figure 2 - Monthly distribution of the total number of fires

The temporal distribution of the total number of fires by month of the year shows a great concentration in the late summer and in the autumn with a peak in September. In the last months of the year, the number of fire incidents decreases, the lowest values being registered in December. Although there are more heating devices functioning which increases the risk of fire incidents, the cold season is characterized by low values in the number of fires. In February the number of incidents is similar to December, while in January there were more fires. From March until May the number of fires decreases, while from May until September 
there is a constant increase. In Figure 2 one can assess whether the values are constant over the years or one single year influences the entire situation. For example, the value registered in September is clearly influenced by the value registered in 2012. This situation can be explained by the fact that in 2012 the Eastern side of Romania was affected by a very serious draught, which contributed to vegetation fires. Another explanation resides in the fact that in August and September a large share of people is on vacation, which means that the households are less strictly monitored, compared to the rest of the year. November is one of the months that registered constant values of the number of fires in all the years. The majority of the months have values that vary from one year to another, which shows the unpredictable character of fire events.

The daily distribution of the number of fires by cause of ignition does not vary too much, but it is noticeable that the number of fires from the weekend is nearly equal to the number of fires that occurred from Monday to Friday. This is also acknowledgeable in the case of fires causes by smoking or open fire. The fires caused by electrical malfunctions tend to concentrate mainly in weekdays, which can be explained by an overuse of the power grid and household appliances.

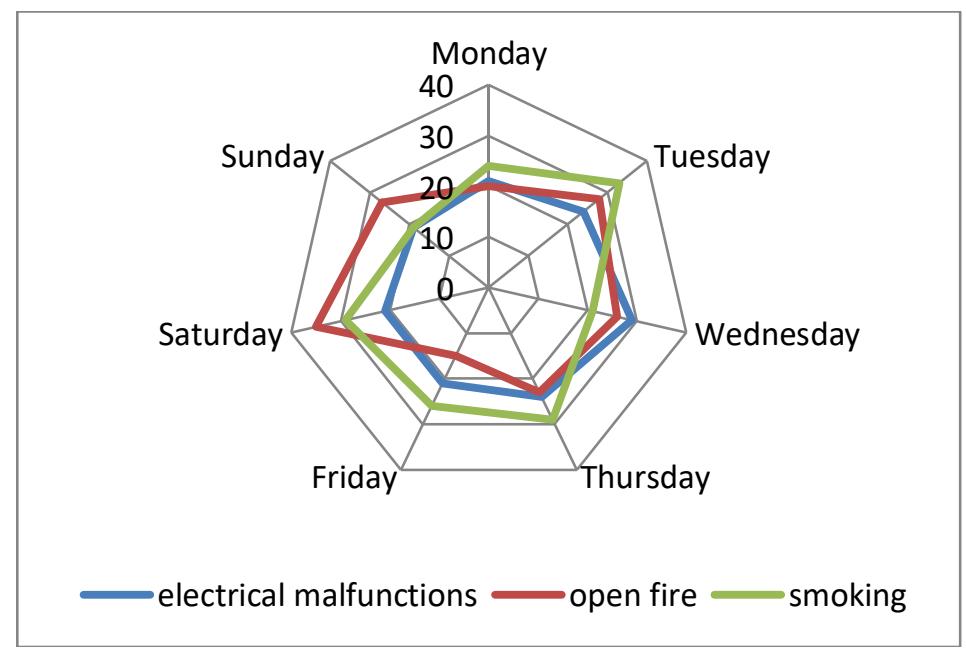

Figure 3 - The daily distribution of the number of fires by cause of ignition

If the daily distribution is not very variable, the hourly distribution (Figure 4) shows a different pattern from one hour interval to another. We decided to split the day in 8 intervals of 3 hours each, for a better visualization of the data. The graph shows a clear difference between day and night, as the majority of firefighting interventions took place during the day. 
The number of interventions increases from 9 am and reaches a peak in the interval $12-3 \mathrm{pm}$. After $3 \mathrm{pm}$, the number of interventions slowly decreases, but still in the interval 9-11.59 pm the values registered are rather high. During the night the number of interventions is decreasing until the hour interval 6-9 am, which registers the fewest interventions. Some years contributed more than others to the number of fires registered in the time intervals, but the differences aren't that significant. Even so, there are 2 time intervals that seem to exhibit a different pattern than the rest, in the sense that the number of firefighting interventions decreased since 2012: 09-12 am and 9-23.59 pm. The interval 12-3 pm registers different values every year, but with the exception of 2016 the values are similar. A comparable situation repeats itself for the intervals 3-6 PM and 6-9 pm, another link between these 3 being the fact the year of 2013 contributes less than the others, but this situation is consistent with the total number of fires registered in 2013 (the lowest number of fires, except 2016).

The time interval that registers the majority of fires corresponds to the time of the day when the dwellings are less supervised due to the fact that the majority of people are at work, which increases the possibility for an incident to occur. Most of the fires registered in this time interval are generated by electrical malfunctions, smoking and outdoor open fire; except for the fires generated by electrical faults, the rest of the fires that occur are related to acts of negligence of the population.

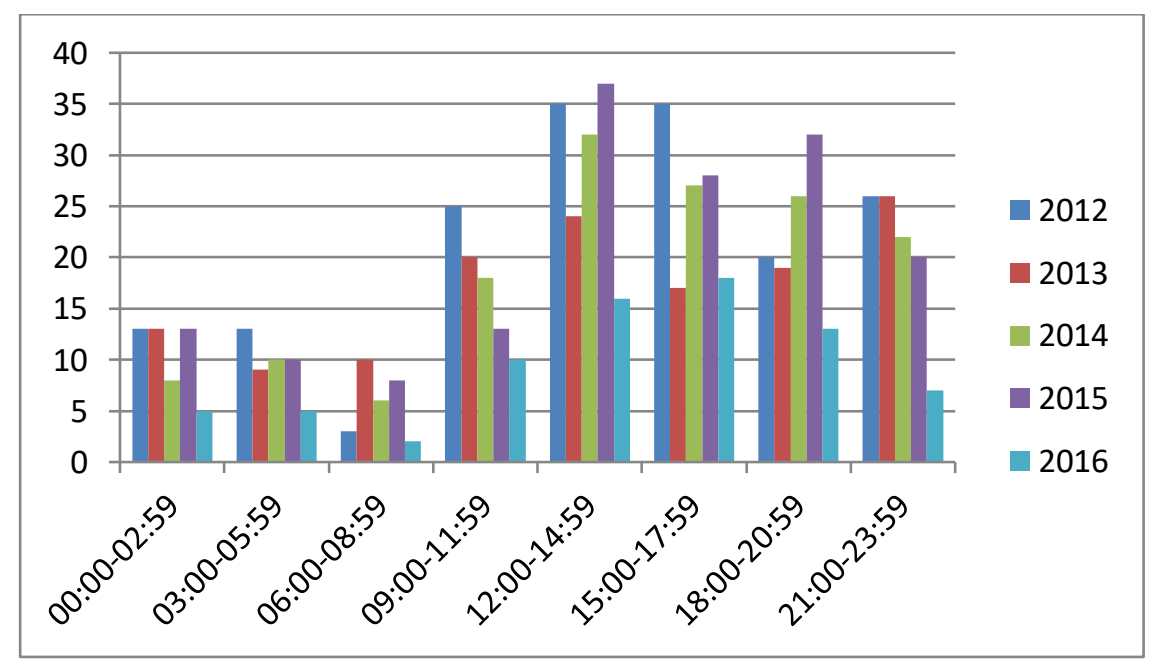

Figure 4 - The hourly distribution of the total number of fires by year 
3.3 Spatial analysis. The spatial distribution of the number of fires per district follows a visible pattern across the city. On the map below (Figure 5) one can acknowledge that the axis NNW-SSE concentrates the districts with the highest number of fires and the Eastern and Western parts of the city are characterized by smaller number of fires. This distribution appears to be connected to the main types of buildings of each district. A larger number of fires tend to concentrate in the neighborhoods with multiple functions (administrative, cultural and residential) and in the industrial area, the causes being more diverse in this situation. There are also a few locations in the areas of collective dwellings that concentrate many fires and in comparison with the axis NNW-SSE, but these areas have lower values if we take into account the ratio between the number of fires and a number of 1000 inhabitants, because the density of the population is higher compared to other districts. In this case, the uniformity of built-up area of the district restrains the causes of ignition. The districts of the city with individual dwellings have higher densities of fires compared to those described before, as one would expect, because a bigger number of fires occurred in an area with a lower population density.

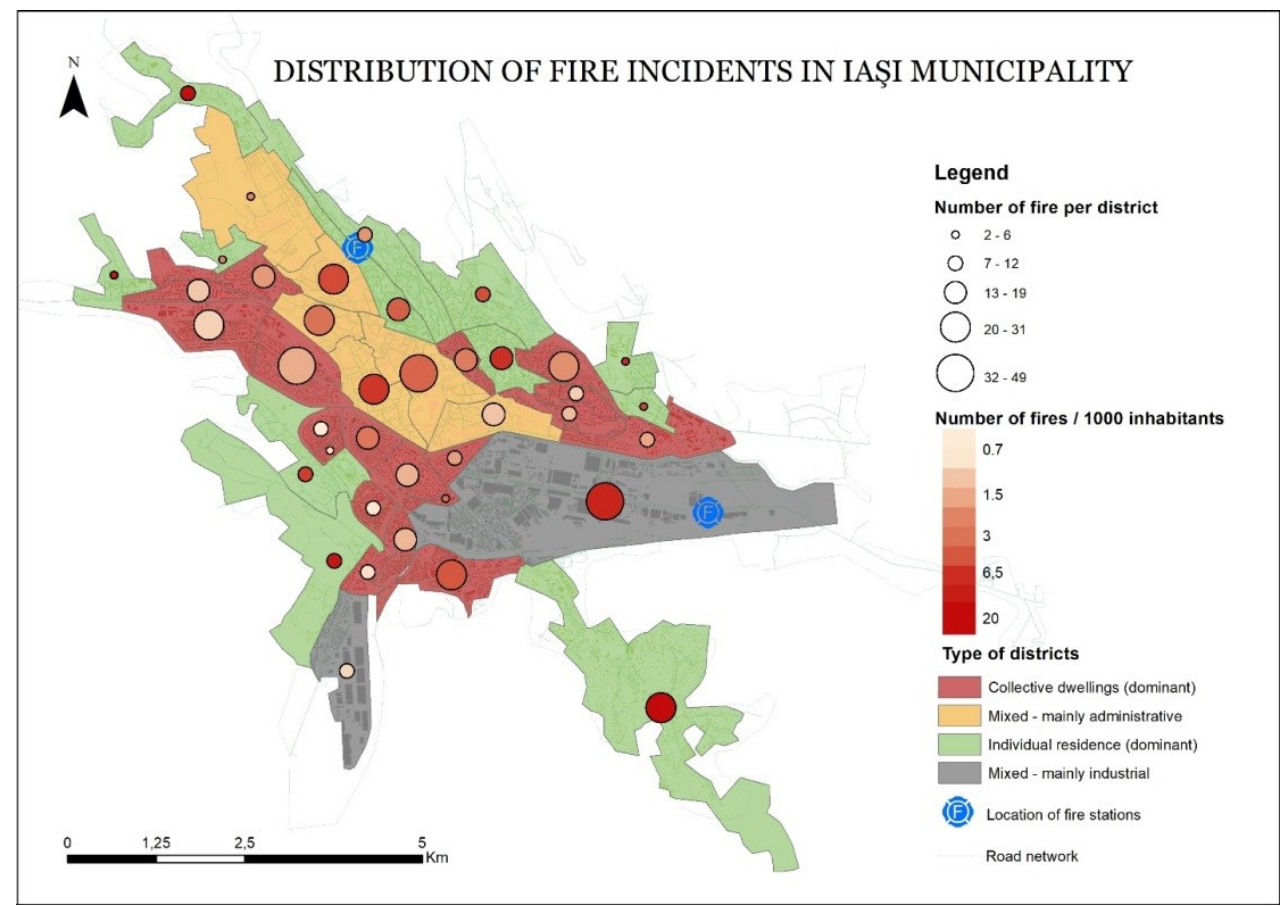

Figure 5 - The spatial distribution of fire incidents in Iaşi Municipality (2012 - 2016) 
The industrial area stands out through a big number of fires at the district level and also a high number of fires/ 1000 inhabitants, a situation which appears not only because of the lower total number of resident population, but also because of the presence of brownfields, many of the buildings losing their function and being abandoned. These buildings in ruins became a perfect place for the homeless population that uses garbage as fire material. This situation is frequent and has been often the cause of significant fire event. The number of fires per district offers a general idea on fire risk for each neighborhood, but the density of the fires is even more relevant for assessing the exposure of population.

Figure 6 illustrates a typology of the districts regarding the main type of fire that took place in an area. Some of the districts appear to be dominated by a single type of fire; others represent a combination of at least 2 main types. The majority of the fires in the city are residential and, in some districts, they are followed by other types, such as vegetation and dumpster fires.

The industrial area is a mosaic of different types of fires. In the Northern and Southern part of the city, where mostly individual dwellings dominate the landscape, the main types of fires are vegetation fires, whereas the East is mainly threatened by dumpster fires. Also, at the periphery, more types of fires occur in addition to residential ones.

\section{TYPES OF FIRE IN IAŞI MUNICIPALITY AT DISTRICT LEVEL}

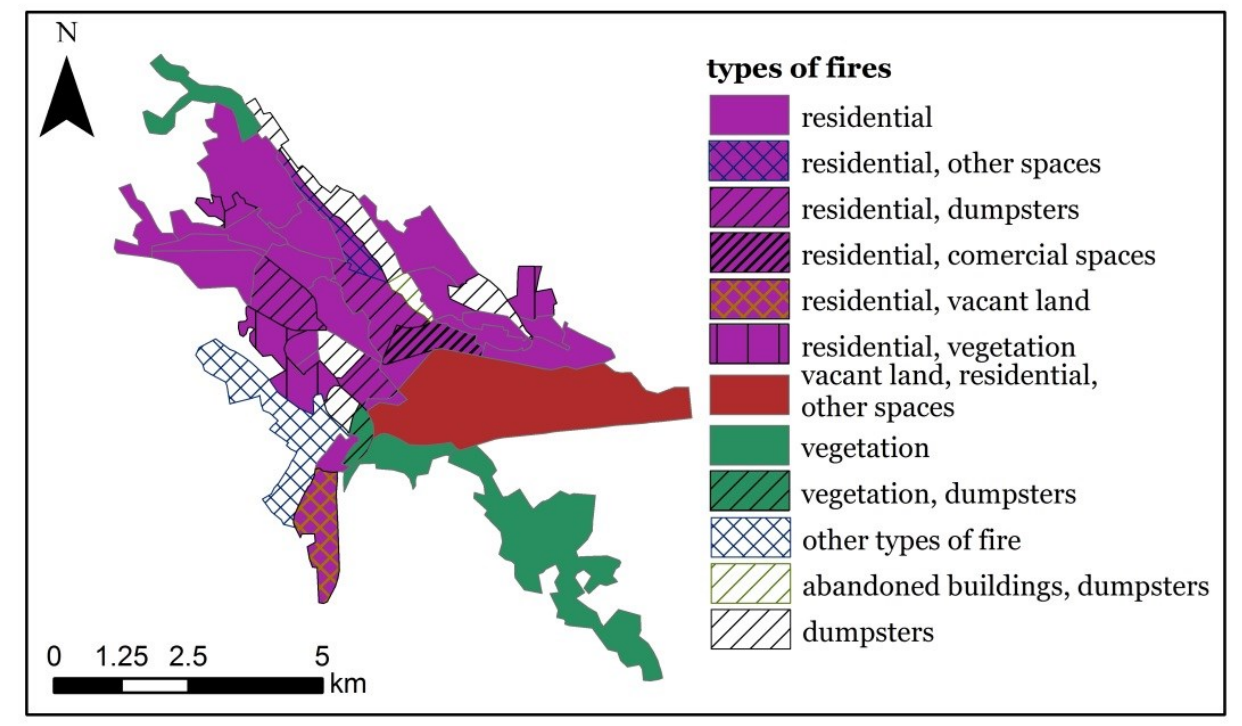

Figure 6 - Types of fire in Iaşi Municipality at district level 
The location quotient for residential fires shows a concentration in the districts located in the Eastern and North-Western part that is almost double compared to the rest of the city. These areas are dominated by individual housing, which can explain such high values of the location quotient through the fact that the number of residential fires is higher than it is in other districts and the population exposed is lower than the neighborhoods with collective housing.

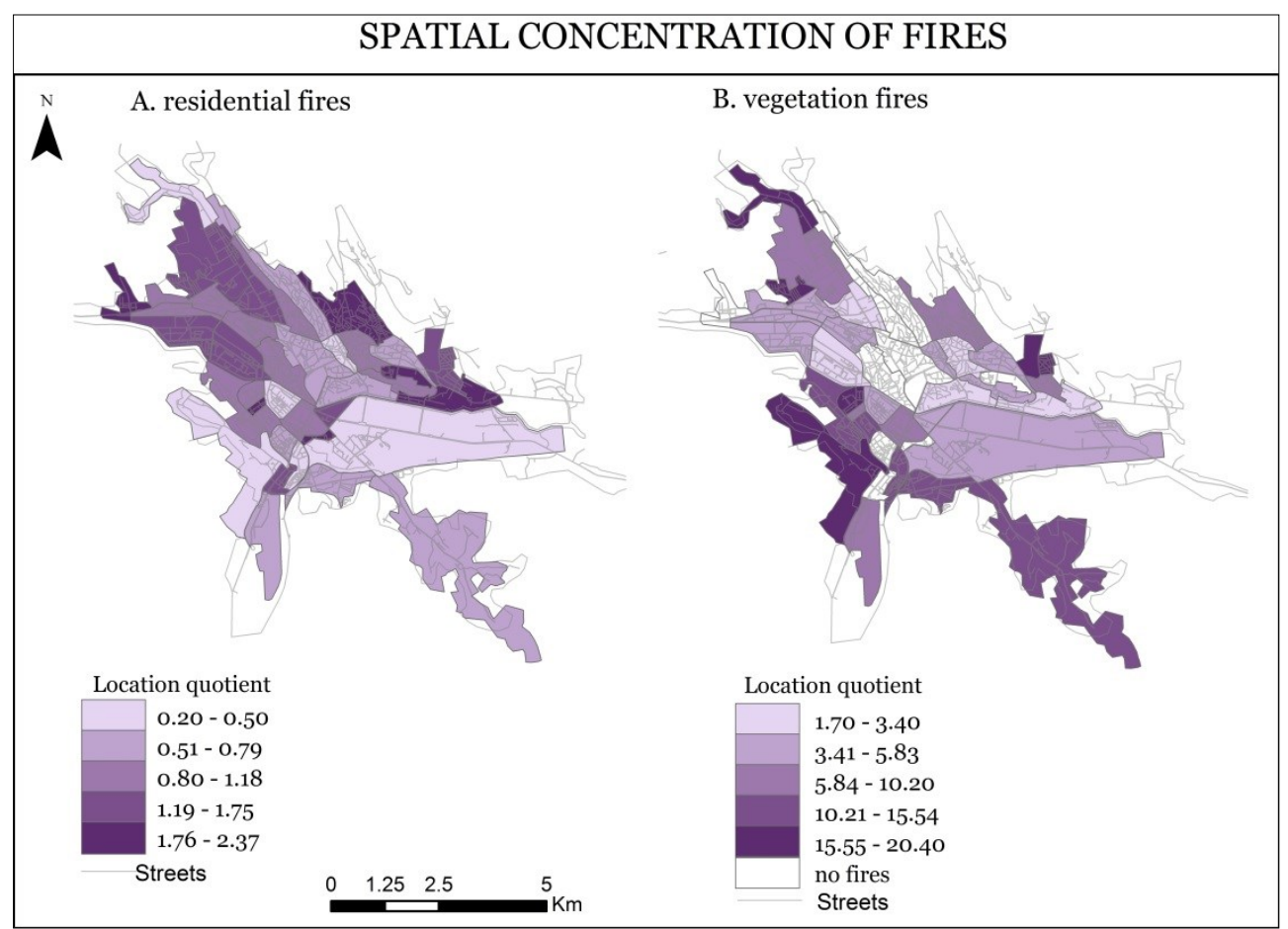

Figure 7 - Spatial distribution of the location quotient at district level in Iaşi Municipality

High values of this indicator, for both residential and vegetation fires, are recorded in neighborhoods with a peripheral location, which have vegetation areas that are neglected and without specific planning; in addition, these districts have individual dwellings. Also, the high values are explained by the small number of inhabitants. Peripheries are areas of transition between urban and rural, characterized by limited access to utility networks, new buildings that are not permanently monitored, isolated from the rest of the city due to an incomplete or non-existent street network; the lack of access routes along with the low degree of supervision make these buildings more prone to fire and the access of the 
intervention crews is difficult. On the other hand, other peripheral areas are known as slums, which are characterized by very poor populations that do not have the financial means needed to buy building materials and improvise with materials that are often flammable and contribute to the spread of fires. This category of population improvises in the cold season heating appliances that do more harm than good. The periphery also has spaces with spontaneous vegetation, which during the summer drought dries intensely, favoring the occurrence of fires and spreading over larger spaces propagating to neighboring buildings.

\section{Discussions and Conclusion}

The outcomes of this preliminary assessment of fire incidents occurrence in Iasi Municipality reveal some important features of their distribution at different temporal and spatial scales.

The temporal analysis of the fire incidents showed that even if there is no pattern in distribution to maintain over the years, there are several constant occurrences. The hourly and monthly distributions have similar structures and revealed that fires are dependent on factors such as seasonality, the intensity of domestic activities, or the presence or absence of people from dwellings. The spatial distribution of fires indicated that the density of population has a great influence, the cartographic results revealing that the densely populated districts registered a higher number of fires.

Both spatial and temporal analysis pointed out that the patterns depend on a multitude of factors from technological to environmental and from sociodemographic to economic. In the case of collective dwelling districts, the presence of a 'guardian' (someone who stays at home during the day or a device that alerts the population) contributes to a higher prevention rate. In case of a fire, the 'guardian' helps limit the damages. In the neighborhoods with a population at risk of social exclusion, the occurrence of fires is higher. That can happen because of different behavioral issues. For example, habits such as smoking or alcohol consumption annihilate the role of the 'guardian' and transform it in a perpetrator. Poverty also leads to poorly equipped dwellings or improvised construction materials.

The spatial analysis showed certain hot-spots where the number of fire occurences is higher, and these areas are located mainly on the periphery. In these districts, the ,guardian' is missing because of a low population density, so the impact of a fire is much higher.

This analysis used simple instruments in order to observe some similarities in the distribution of fire incidents and is a first step for a more detailed analysis of the fire risk. A future study should take into account the vulnerability patterns 
(social, economic, infrastructural vulnerability), which would give a better insight on the causality of fire incidents and their distribution in Iași city.

\section{References}

1. Asgary, A., Ghaffari, A., Levy, J. (2010), Spatial and Temporal Analyses of Structural Fire Incidents and Their Causes: A Case of Toronto, Canada, Fire Safety Journal 45(1): 44-57. https://doi.org/10.1016/j.firesaf.2009.10.002

2. Banica, A., Rosu, L., Muntele, I., Grozavu, A., (2017), Towards Urban Resilience: A Multi-Criteria Analysis of Seismic Vulnerability in Iasi City (Romania), Sustainability 9 (2): 270 . https://doi.org/10.3390/su9020270

3. Benedek, J., Ciobanu, S. M., \& Man, T. C. (2016), Hotspots and social background of urban traffic crashes: A case study in Cluj-Napoca (Romania), Accident Analysis \& Prevention, 87, 117-126. https://doi.org/10.1016/j.aap.2015.11.026

4. Chhetri, P., Corcoran, J., Stimson, R.J., Inbakaran, R., (2010), Modelling Potential Socio-Economic Determinants of Building Fires in South East Queensland, Geographical Research 48(1):75-85. https://doi.org/10.1111/j.1745-5871.2009.00587.x

5. Clark, A., Smith, J., Conroy, Carole, (2015), Domestic Fire Risk: A Narrative Review of Social Science Literature and Implications for Further Research., Journal of Risk Research 18 (9): 1113-29. https://doi.org/10.1080/13669877.2014.913660

6. Corcoran, J., Higgs, G., Brunsdon, C., Ware, A., Norman, P., (2007), The use of spatial analytical techniques to explore patterns of fire incidence: A South Wales case study, Computers, Environment and Urban Systems, Volume 31, Issue 6: 623-647, ISSN 0198-9715 https://doi.org/10.1016/j.compenvurbsys.2007.01.002

7. Corcoran, J., Higgs, G., Higginson, A. (2011). Fire incidence in metropolitan areas: A comparative study of Brisbane(Australia) and Cardiff(United Kingdom), Applied Geography, 31(1), 65-75. https://doi.org/10.1016/j.apgeog.2010.02.003

8. Fahy, R., Miller, A., (1989), How being poor affects fire risk, Fire Journal 83: 28-30.

9. Ganteaume, A., Camia, A., Jappiot, M., San-Miguel-Ayanz, J., Long-Fournel, M., Lampin, C., (2013), A Review of the Main Driving Factors of Forest Fire Ignition Over Europe. Environmental Management 51 (3): 651-62. DOI 10.1007/ s00267-012-9961-z

10. Himoto, K., Tanaka, T., (2008), Development and validation of a physics-based urban fire spread model, Fire Safety Journal, 43(7), 477-494. https://doi.org/10.1016/j.firesaf.2007.12.008

11. Jennings, C. R., (1999), Socioeconomic Characteristics and Their Relationship to Fire Incidence: A Review of the Literature., Fire Technology 35 (1): 7-34.

12. Jennings, C. R. (2013), Social and economic characteristics as determinants of residential fire risk in urban neighborhoods: A review of the literature, Fire Safety Journal, 62, 13-19. https://doi.org/10.1016/j.firesaf.2013.07.002

13. Li, S., Davidson, R. A., (2013), Parametric study of urban fire spread using an urban fire simulation model with fire department suppression, Fire Safety Journal, 61, 217-225. https://doi.org/10.1016/j.firesaf.2013.09.017 
14. Merciu, C., Ianos, I., Merciu, G.-L., Jones, R., Pomeroy, G. (2018), Mappingaccessibility for earthquake hazard response in the historic urban centre of Bucharest, Natural Hazards and Earth System Sciences, 18(7), 2011-2026. https://doi.org/10.5194/nhess-18-2011-2018

15. Nicolopoulos, N., Murphy, M., Sandinata, V. (1997). Socio-economic characteristics of communities and fires, In Statistical research. Sydney: NSW Fire Brigades.

16. Roșu, L.I., Blăgeanu, Alexandra, (2015), Evaluating Issues and Performance of a Public Transport Network in a Post-Communist City Using a Quantitative Spatial Approach., Urbani Izziv 26(2):103-16. DOI:10.5379/urbani-izziv-en-2015-26-02-002

17. Schaenman, P., Hall, J., Schainblatt, A., Swartz, J., Karter, M. (1977), Procedures for improving the measurement of local fire protection effectiveness. Boston: National Fire Protection Association.

18. Sentz, R., (2018), Understanding Location Quotient. EMSI (blog), accessed 16/10/2018. https://www.economicmodeling.com/2011/10/14/understanding-locationquotient-2/

19. Southwick, L., Butler, R.J., (1985), Fire department demand and supply in large cities, Applied Economics 17:1046-1050. https://doi.org/10.1080/00036848500000066

20. Stephens, S. L., Collins, B. M., Biber, E., Fulé, P.Z., (2016), US federal fire and forest policy: Emphasizing resilience in dry forests, Ecosphere 7(11), e01584. https://doi.org/10.1002/ecs2.1584

21. Thomas, G.C., Cousins, W.J., Lloydd, D.A., Heron, D.W., Mazzoni, S., Post-earthquake fire spread between buildings estimating and costing extent in Wellington, Proceedings of the 7th Symposium, International Association for Fire Safety Science, 2002, pp. 691-702. doi:10.3801/IAFSS.FSS.7-691

22. Tsenkova S., Nedović-Budić Z. (2006), The post-socialist urban world. In S. Tsenkova, Z. Nedović-Budić (Eds.), The Urban Mosaic of Post-Socialist Europe (pp. 349-366). Physica-Verlag HD. Retrieved from http://link.springer.com/10.1007/3-7908-17279 18. https://doi.org/10.1007/3-7908-1727-9_1

23. Vasiliauskas, D., Beconytè, G., (2015), Spatial analysis of fires in Vilnius city in 20102012., Geodesy and Cartography 41 (1): 25-30. https://doi.org/10.3846/20296991.2015.1011862

24. Yao, J., Zhang, X., Murray, A. T., (2019), Location optimization of urban fire stations: Access and service coverage, Computers, Environment and Urban Systems, 73, 184-190. https://doi.org/10.1016/j.compenvurbsys.2018.10.006

25.***Bulletin World Fire Statistic, (2014), 29. The Geneva Association. https://www.genevaassociation.org/sites/default/files/research-topics-documenttype/pdf public//ga2014-wfs29.pdf.

26.***CTIF, (2017), World Fire Statistics 2017, 22, Center of Fire Statistics, International Association of Fire and Rescue Services.

27.***FEMA, (1997). Multi Hazard Identification and Assessment, Washington, D.C. :FEMA.

28.***IGSU, (2016), Analiza statistică privind acţiunile de prevenire, pregătire şi răspuns in situaţii de urgenţă pentru perioada 01.01.2016 - 31.12.2016, Ministerul Afacerilor Interne Departamentul pentru Situaţii De Urgenţă, Inspectoratul General pentru Situaţii De Urgenţă. https://www.igsu.ro/documente/informare_publica/evaluari/ Analiza\%20Operativa\%2 001.01.2016\%20-\%2031.12.2016.pdf. 